\title{
INSISTENCIAS ELEMENTALES
}

\section{SOBRE URBANISMO}

$E_{L}$ eco de reiteradas manifestaciones en torno a la idea de adscribir con carácter exclusivo a determinada disciplina unilateral una íntegra capacidad urbanística, produce una impresión semejante a la que se ocasiona en achaques médicos cuando, tras un aparente arraigo de una terapéutica y en el curso del consiguiente tratamiento progresivo, se produce en la naturaleza enferma un incidente cualquiera, acusador de lo superficial de la mejoría, que obliga a desandar caminos de optimismo y comenzar de nuevo, con firmeza y precaución, desde los pasos primeros, que sirvan de arranque al intento de reeducación inicial y curación del enfermo.

En el campo del urbanismo, en ese figurado plan de tratamiento racional de la ciudad, se apunta también, a veces, la necesidad de volver a los primeros pasos elementales, al observar el brote de errores sustantivos a través de conceptos que cumple corregir; y quien lleva su vida profesional, de un cuarto de siglo largo, ligada desde su principio a este género de afanes (aunque diste mucho de atribuirse presuntuosamente ninguna calidad de doctorado), considera necesario dedicar alguna ocasión que, como ésta, se le ofrece, al intento modesto de poner alguna claridad en la maraña que vienen a formar con las ideas, unos conceptos construidos sobre ellas mismas, con riesgo de perturbar su esencia y producir ese desorden que sigue al uso equivocado de las cosas y nace de una falta de exactitud al construir o interpretar una definición.

No se encuadra ciertamente en un marco de perfección el concepto de urbanismo, sucediendo en nuestro idioma algo parecido a lo que acontece en los paísés anglosajones con su "town-planing", cuya composición no llega a abarcar todo 
el problema significado en cada uno de sus componentes. Este achaque común a otros idiomas requiere en el nuestro sli peculiar matiz. En ocasión parecida a la presente, me atreví a señalar nuestra situación desventajosa a este respecto; consiguiente a faltar, de siglos atrás, un sentido clásico en nuestra educación elemental, que conduce a ignorar las bases radicales de nuestro idioma y a usarlo alegremente, con personal ajuste a la peculiar acepción que atribuyamos a cada vocablo, concreto y terminante de por sí; resultando de ello el desorden de una torre de Babel. $\mathrm{Y}$ citaba entonces, por vía de ejemplo, cómo existen hoy (entre gentes que se tienen por versadas en materia de urbanismo) tres acepciones dispares de este concepto, encerradas en tres pequeñas parcelas de su amplísimo recinto, según las cuales cada uno circunscribe a su pequeño urbañismo ei problema capital; y así resulta que éste depende para uno en toda su integridad del trazado utilitario de unas calles, en tanto que otro lo sitúa en la fantasía de unas perspectivas, siendo para el tercero un negocio de una venta de terrenos.

El buen uso de las cosas en materia de urbanismo y ei orden resultante constituye un proceso de claridad y precisión que sólo puede salir de atribuciones adecuadas a una definición exacta, nacida del dominio absoluto alcanzado en todos sus aspectos, considerados desde todos sus ángulos, como único medio de alcanzar una sintetización tan eficaz y completa como indispensable.

Será tal vez preciso llegar a la definición estricta que aquí nos cumple, uniendo sucesivamente conceptos y opiniones formados sobre resultados producidos en experiencics positivas y evidentes, resumiendo luego todas ellas en un acuerdo que las convierta en una conclusión esencial y terminante. Elegimos este arbitrio de recurso a afirmaciones ajenas universalmente autorizadas, para sosiego de curiosos aficionados, más que para alivio de caminanteș en este, a lo que parece, largo viaje apenas iniciado cuando otros llevan varias décadas de fructífera experiencia.

$\mathrm{Y}$ para arrancar de lejos, dejando para más adelante el análisis de las experiencias nórdicas y sajonas en Europa, elegiremos hoy el ejemplo de Chicago, donde hace ya treinta años abordaron el problema del modo que hoy culmina en la Junta de Reconstrucción de Madrid. Y en ese ejem- 
plo vivo del que no puede deducirse prejuicio alguno sino resultádos evidentes de una experiencia práctica que nos precede en más de un cuarto de siglo, tenemos la opinión de Carlos H. Wacker, Presidente de la "Chicago Plan Comision", que al enfrentarse con el problema del urbanismo, lo define así:

"Crea y promueve el tráfico, suministrando al comercio un cauce fácil a su establecimiento y desarrollo; alimenta el desenvolvimiento de la ciudad, haciendo económico todo género de negocios; acrece y asegura el valor de la propiedad inmueble, evitando los malos resultados de una edificación anarquizante; hace eficaz la vida y el trabajo ciudadanos al ahorrar tiempo y coste en el obligado tránsito de gentes y mercancías; y, sobre todo, garantiza a la ciudad que lo resuelve un perfeccionamiento material y moral de si vida y sus costumbres."

En otros términos, define el urbanismo como una ciencia de antigüedad igual a la de la primera ciudad organizada, como proceso idéntico a la habitabilidad, al ser' la creación de la residencia humana la fase primera, el anticipo en escala reducida de la residencia social que es la ciudad.

Bajo los principios contenidos en estas definiciones se desenvuelve la "Chicago Plan Comision" con un sentido de permanencia, patentizado en el hecho de invertir ocho años en sus estudios de información y en sús trabajos, girando éstos en torno del arquitecto Burman, como centro y eje, no sólo de la mejor asistencia técnica, sino del más eficaz consejo de los hombres de negocio, que representan el lado promotor y dan a las amplias concepciones de la técnica el práctico sentido de una posible realización.

Con arreglo al ejemplo que enunciamos, se otorga en él muy especial cuidado a las dos fases que encierra en sí el ciclo de urbanismo, considerándolo como profesión al abordarse el aspecto técnico del problema, y como organización social al plantearse lo que pudiéramos liamar su poder dinámico, en cuya relación ha de tenerse en cuenta que las cualidades del proceso, en su conjunto, dependen tanto del sentido racional de observación, de la compulsa y equilibrio de opiniones, como del dominio técnico y la hábil aplicación de sus

12 principios, en los que ha de intervenir como esencial factor 
un sentido que perciba y mida el desarrollo físico de la ciudad en sưs múltiples y numerosas reacciones biológicas.

El urbanismo, como profesión, desborda los límites de cualquiera de las existentes, al exigir la general concurrencia de todas las técnicas a una labor conjunta, donde han de ser cuidadosamente atendidas la salud, la conveniencia, la economía, el acomodo, la belleza y cuantas circunstancias contribuyen a mejorar la viça humana; donde cada técnica tiene su ajuste exacto y su preciso encaje con arreglo a su especialismo, tanto como a su funcionamiento consiguiente, a su peculiar formación para producir una labor medida y proporcionada, dependiente de las demás, colindante con ellas y sujetas todas a un sentido ordenador que haga del total ensamblaje un organismo armonizado bajo los principios que impone la dignidad humana.

$Y$ del mismo modo que en la residencia, como fase primera del urbanismo, se suma el perfeccionamiento de todas las técnicas para lograr un conjunto que procure el mayor acomodo a la vida humana con arreglo a un sentido ordenador que mida y proporcione el lugar y la extensión en que cada una intervenga, así en la creación de la ciudad ha de seguirse el mismo sentido de medida y proporción para todas las actividades que conjuntamente crean una residencia digna de la sociedad.

El urbanismo, como organización social, desborda el ámbito municipal al requerir la indispensable creación de una entidad especialmente dedicada a resolver un problema donde han de concurrir simultáneamente las asistencias interesadas de autoridades y organismos de todo orden, que en la urbe representan una fuerza vital, una actividad, una razón de ser y de existir, constituyendo ciertamente un mosaico de intereses que precisa articular en su justa proporción, encuadrados en un sistema funcional que la experiencia hace autónomo, con personalidad jurídica y poder ejecutivo, lo que no quiere significar una sistemática eliminación de los Municipios como tal mecanismo accionador, sino simplemente dejar establecido que no puede caerse en la rutina de atribuírle automáticamente una adscripción y un estanco, para el que rara vez están capacitados en razón de su estructura, ausente del sentido de permanencia que indispensablemente ha de presidir un empeño de semejante porte. 
Es frecuente ver el uso equivocado que se hace del concepto de urbanismo, donde existen multitud de Municipios que sólo tienen planes fragmentarios (para no hablar de la absoluta carencia de sus planes respectivos) que califican de urbanismo cuando son precisamente su negación, porque el ensanche de una calle o de una plaza, la apertura de una vía o la creación de núcleos 0 cualquiera otra mejora urbana sin nexo o netamente contrarios a una concepción de la ciudad, son pura y simplemente "antiurbanismo" al crear formas erróneas en el ejercicio de unos principios equivocados.

La Dirección General de Administración Local enfoca hoy el problema del urbanismo con una amplitud de visión enaltecedora y digna de los máximos cuidados. Otras entidades abordan todos estos problemas en todas sus fases.

Cuantas entidades se afanan en estas inquietudes harán bien en establecer una previa claridad en las ideas, que se imponga como único medio eficaz para lograr que los impulsos diversamente repartidos se unifiquen bajo el signo común de una labor nacional.

Pedro Muguruza Otaño
Director General de Arquitectura 